\title{
Decision making under risk of predation in the western whip snake Hierophis viridiflavus
}

\author{
ROGER MEEK* \& LUCA LUISELLI
}

Institute for Development, Ecology, Conservation and Cooperation, via G. Tomasi di Lampedusa 33, 00144 Rome, Italy

*Corresponding author e-mail: rogermeek85@aol.com

$T^{\text {neter }}$ heory predicts that during movement the decisions made by animals are influenced by the costs and benefits of movement and that this in turn is driven by landscape structure, for example degree of habitat patchiness and quality of the habitat matrix including predator and prey densities (e.g. Lima \& Dill, 1990; Fahrig, 2007). Patch selection may vary not only in terms of foraging profitability, but also in terms of predation risk; although species that actively forage may encounter more prey species than ambush/sit and wait predators they are also likely to come into contact with more predators (Huey \& Pianka, 1981). Movement may disrupt the benefits of camouflage and hence the risk levels involved in extensive movement require the evolution of a range of defence behaviours in the event of encountering a predator. Here we describe what appears to be a previously undocumented defensive behaviour in the western whip snake Hierophis viridiflavus.

The western whip snake is a habitat generalist, often found along woodland edges, bocages (i.e. farmland bordered by two hedgerows) where it forages widely; in other regions of western Europe it has been reported foraging up to $3 \mathrm{~km}$ from the winter den (Ciofi \& Chelazzi, 1994). In the study area, this species can approach almost 2 metres in total length, and preys on fast moving animals including lizards, small mammals, birds and, amphibians (Rugiero \& Luiselli, 1995; Capizzi \& Luiselli, 1996). These snakes are extremely fast moving, so usually when basking or moving and encountering a potential predator their initial response will be to flee into cover. If caught or trapped they will bite fiercely and if this is ineffective some individuals will feign death (e.g. Rugiero, 1999). This range of behavioural responses is clearly effective since some individuals of $H$. viridiflavus attain ages of around 20 years or so (Fornasiero et al., 2016).

In anthropogenically modified environments, risk of predation during foraging is likely to increase due to increased frequency of contact with humans, domestic dogs and cats, among others (Bonnet et al., 1999; Rugiero \& Luiselli, 2004; Meek, 2012). In this note we describe an anti-predator response by foraging $H$. viridiflavus when encountering humans and dogs, consisting of a combination of remaining completely motionless together with crypsis. All snakes described below were adults of at least 1 metre and were encountered during fieldwork on the edge of the village of Chasnais $\left(46^{\circ} 27^{\wedge} \mathrm{N} ; 1^{\circ}\right.$ $53^{\prime} \mathrm{W} ; 25 \mathrm{~m}$ asl) in Vendée, western France.

The first observation of 'total immobility' was during late

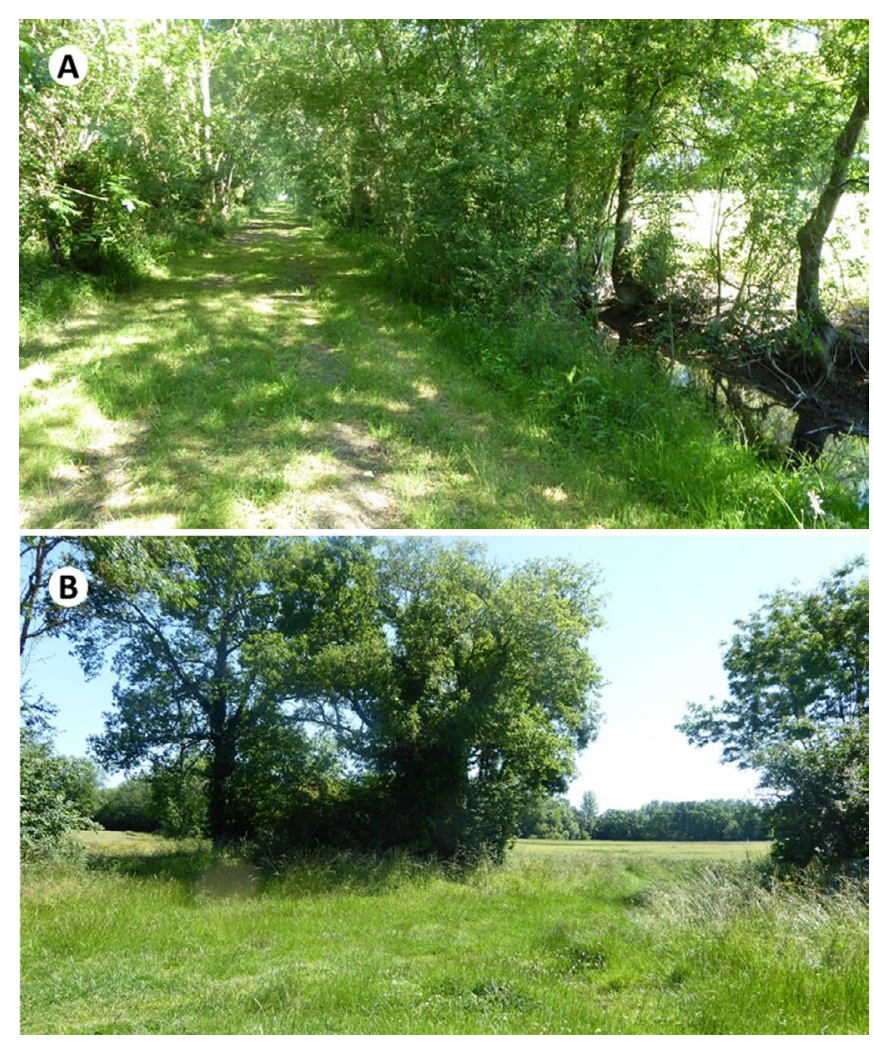

Figure 1. A. Bocage habitat showing the area where the snake described in Example 1 was encountered. The snake was moving towards the observer on the right of the picture but on reaching the grass became motionless (see text), B. Opening in the hedgerow (right) where the snakes in Example 2 (from left to right) and Example 3 (right to left) were attempting cross the clearing. Opening on left shows the direction of the hedgerow, which eventually leads to the Bocage habitat in A.

afternoon June 2007 in a bocage area where one of us (RM and 3 dogs) made contact with a $\mathrm{H}$. viridiflavus, approximately 1 metre in length, foraging in a bocage area with a matrix of dappled sunlight. The snake was moving through a small patch of grass between dense covered areas (bottom right in Fig. 1A). With visual contact it became totally immobile with the head raised above the top of the grass, a position it maintained until we had passed. None of the three dogs detected the snake, which moved away into the ditch area (on the right in Fig. 1A) once the 'danger' had passed.

A large adult (likely in excess of $1.5 \mathrm{~m}$ - see Fig. 2) was seen moving along the base of a dried out drainage ditch 


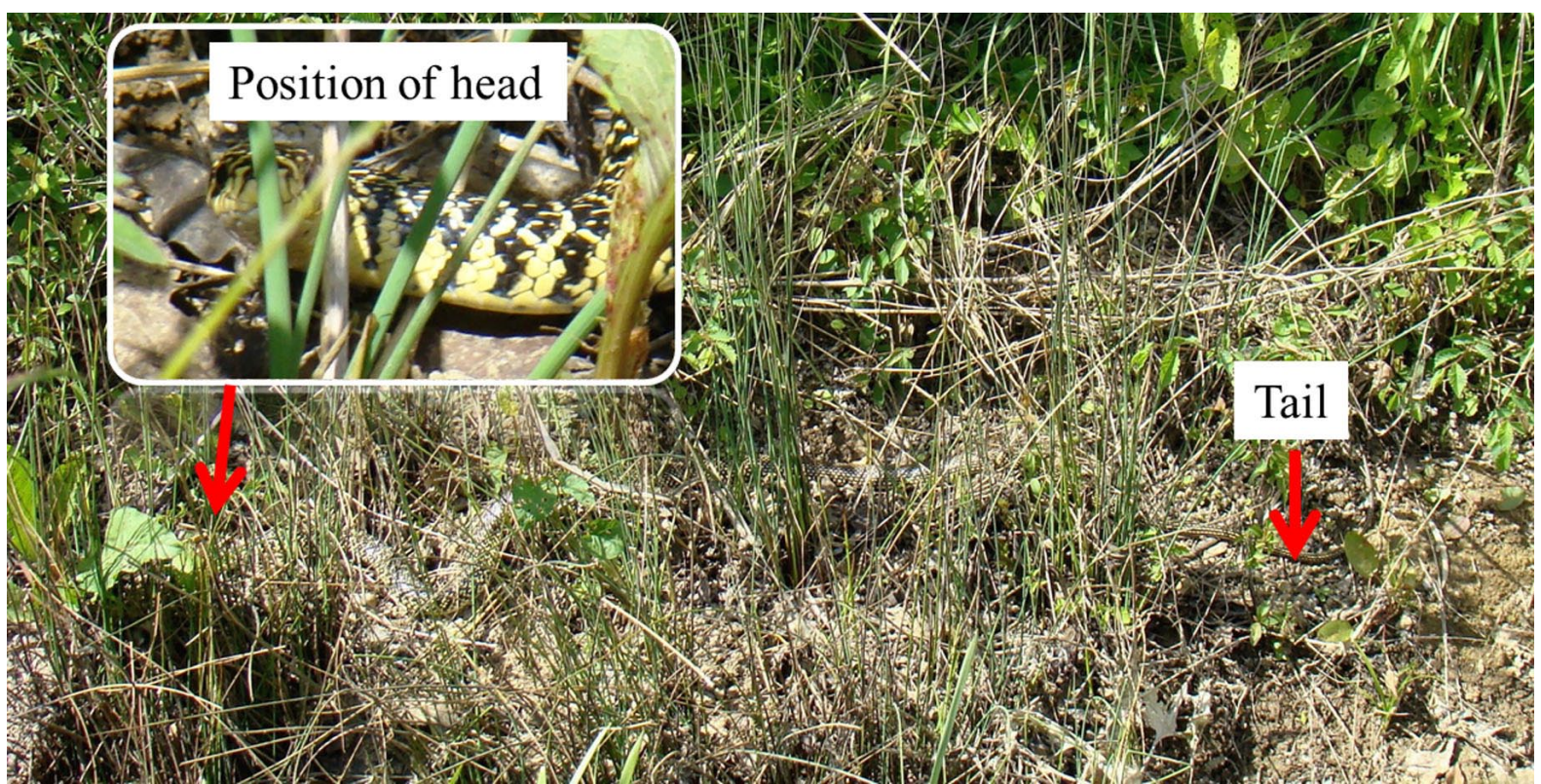

Figure 2. The snake described in Example 2 with insert showing detail of the snake's head, which is partly raised and focused on the observer

at the bottom of a hedgerow (Fig. 2) at around 15:30 $\mathrm{h}$ in June 2014. The snake was apparently attempting to cross the open ground between hedgerows (seen in Fig. 1B) from left to right. As in Example (1) the snake was in light vegetation, mostly grass. On detecting the observer the snake became motionless but remained focused on the observer (insert in Fig. 2). After we passed it retreated up the slope into the hedgerow from where it had emerged.

An adult male $H$. viridiflavus during May 2021 was attempting to cross between two sections of hedgerow from right to left (Fig. 1B). On sighting the observer the snake immediately adopted the total immobility posture with head raised just above the grass (Fig. 3). It was possible for the observer to walk around the snake and take several photographs while in this posture without it attempting to flee. After the encounter the snake retreated back into the hedge.

A basking adult $H$. viridiflavus was encountered in April 2015 situated around $3 \mathrm{~m}$ from dense cover of the hedgerow but in grass swards at heights of around at $20-30 \mathrm{~cm}$ (Fig. 4). A single observer approached the snake along with three dogs but it remained completely motionless, although apparently alert and aware of our approach but moved into the hedgerow after the group's passing.

These observations illustrate that a motionless stance along with crypsis were effective in avoiding detection by domestic dogs. In total, the behaviour formed only $7.3 \%$ of 41 (9.8\% when example 4 is included) encounters with $H$. viridiflavus, in either the hedgerow or bocage. The behaviour has not been observed in the numerous $H$. viridiflavus encountered in natural areas in Italy (LL) and we could find no mention of it in papers on the ecology of this species including movement behaviour (e.g. Capula et al., 1997). Hence it may indeed be an infrequent behavioural response that until now has not been documented. However, as in the use of death feigning (Rugiero, 1999) it may be confined to certain individuals and certain circumstances including

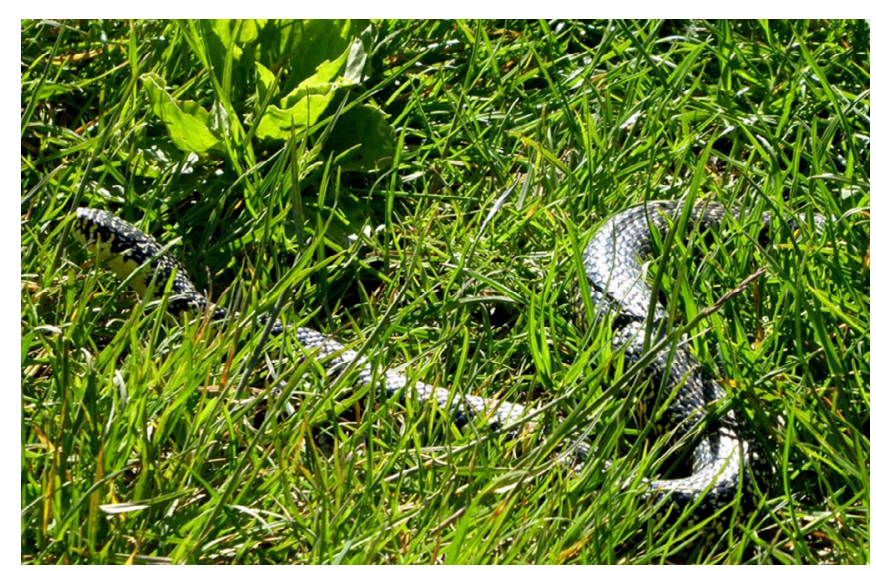

Figure 3. Snake described in Example 3 showing the totally motionless snake just after it has emerged from the hedgerow. Although motionless the head is raised and focused on the observer. It was possible to walk around this snake and take several photographs without it moving.

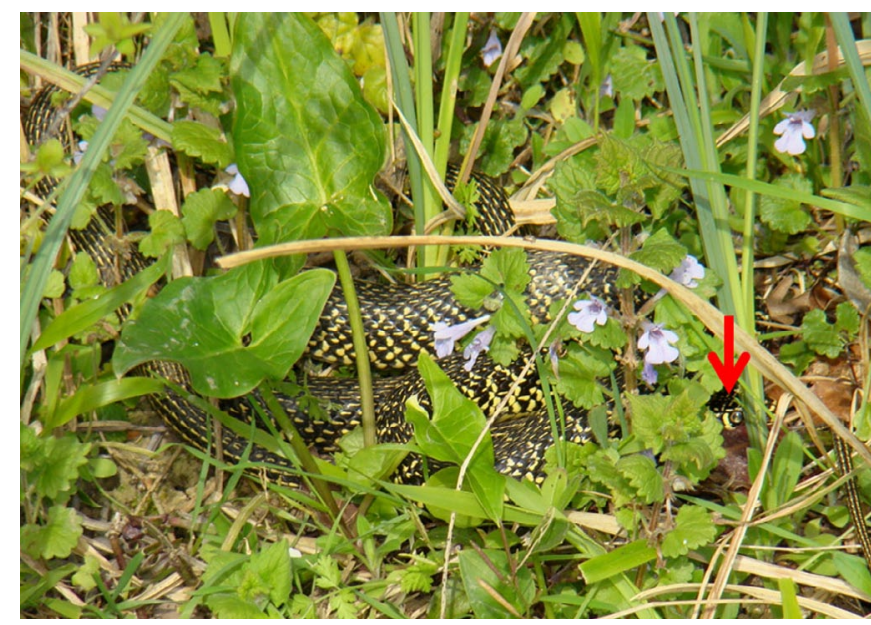

Figure 4. Snake described in Example 4 basking among grass and adopting the motionless behaviour, arrow shows position of head with a clear view of the eye 
in human modified environments. Being motionless as a primary behavioural response is a novel addition to the behavioural sequence in $H$. viridiflavus, which is usually flight followed by fight. Flight mode in $H$. viridiflavus appears to also employ the 'flicker fusion effect' (Umeton, et al., 2017) that can result in a change in the appearance of the snake when it moves rapidly. However, given that this is part of flight behaviour it indicates that in the examples here being motionless has been prioritised over alternative potential defensive options. Initiation of the behaviour will largely depend on the circumstances of the encounter and, critically, who detects the other first, predator or prey, since becoming motionless will be much less effective if it is the snake that is detected first. If the latter, then speed and the possible benefits of flight/ flicker fusion will be the usual primary response. For becoming motionless to be effective the snake must detect the predator first, which was the case in the examples given here. However, it is likely that both the distance between predator and prey as well as light levels in the immediate habitat (low light in Example 1) will influence a snake's decision making. It is also likely that if a snake detects a potential predator above a certain distance away then it is more likely that flight will be employed. The microhabitat of grass swards of around $30 \mathrm{~cm}$ in height probably also influenced decision-making since it is probably a high-risk situation in which to encounter certain predators.

Evolutionary selection for the assessment of risk and selection of optimum behaviour would certainly benefit individual fitness. Risk of predation will depend on lifestyle, quality of the matrix habitat and vary on a seasonal or daily basis. The expansion of fragmented landscapes in urban areas may increase the degree of predation risk from cats and dogs by altering habitat structure and changing the thermal environment (Evans, 2004; Zhou et al., 2011). Hierophis viridiflavus is known for pathway fidelity including to and from egg laying sites (Filippi et al., 2007; Zuffi et al., 2007; Bonnet et al., 2021) and presumably this behaviour is the product of natural selection to reduce predation risk as well as to locate prey. Of interest is that anti-predator behaviour and usual avoidance of high risk habitat in $H$. viridiflavus, especially in human altered landscapes, contrasts with male combat in this species (BHS video, 2021) that often occurs in open locations, including urban gardens, when the combatants appear oblivious to predation risk. This indicates sensitivity to risk is almost completely abandoned under certain circumstances.

\section{ACKNOWLEDGEMENTS}

We thank Prof. Rick Hodges and Dr. Wolfgang Wuster for very useful comments and suggestions on an earlier draft of the manuscript.

\section{REFERENCES}

BHS video (2021). Combat between male western whip snakes Hierophis viridiflavus https://youtu.be/dvwwdrqv6Mk

Bonnet, X., Naulleau, G. \& Shine, R. (1999). The dangers of leaving home: dispersal and mortality in snakes. Biological Conservation 89: 39-50.
Bonnet, X., Jean-Marie Ballouared, J.M., Billy, G. \& Meek, R. (2021). Repeated use of high risk nesting areas in the European whip snake, Hierophis viridiflavus. Herpetological Journal 31: 142-151. DOI: 10.33256/31.3.142150

Capizzi, D. \& Luiselli, L. (1996). Feeding relationships and competitive interactions between phylogenetically unrelated predators (owls and snakes). Acta Oecologica 17: 265-284.

Capula, M., Filippi, E. \& Luiselli, L. \& Jesu, V.T. (1997). The ecology of the Western Whip Snake, Coluber viridiflavus (LACÉPÈDE, 1789), in Mediterranean Central Italy (Squamata: Serpentes: Colubridae). Herpetozoa 10: 65-79

Ciofi, C. \& Chelazzi, G. (1994). Analysis of homing pattern in the colubrid snake Coluber viridiflavus. Journal of Herpetology 28: 477-484.

Evans K.L. (2004). The potential for interactions between predation and habitat change to cause population declines of farmland birds. Ibis 146:1-13. DOI: 10.1111/j.1474-919X.2004.00231.x

Fahrig, L. (2007). Non-optimal animal movement in human altered landscapes. Functional Ecology 21: 1003-1015.

Filippi, E., Anibaldi, C., Capizzi, D., Ceccarelli, A., Capula, M. \& Luiselli, L. (2007). Long-term fidelity to communal oviposition sites in Hierophis viridiflavus. Herpetological Journal 17: 7-13.

Fornasiero, S., Bonnet, X., Dendi, F. \& Zuffi, M.A.L. (2016). Growth, longevity and age at maturity in the European whip snakes, Hierophis viridiflavus and $H$. carbonarius. Acta Herpetologica 11: 135-149.

Huey, R. \& Pianka, E. (1981). Ecological consequences of foraging mode. Ecology 62: 991-999.

Lima, S. \& Dill, L. (1990). Behavioral decisions made under the risk of predation: a review and prospectus. Canadian Journal of Zoology 68: 619-640

Meek, R. (2012). Anthropogenic sources of mortality in the western whip snake, Hierophis viridiflavus, in a fragmented landscape in Western France. The Herpetological Bulletin 120: 4-8.

Rugiero, L. (1999). Death feigning in the Western whip snake, Coluber viridiflavus. Amphibia-Reptilia 20: 438-440

Rugiero, L. \& Luiselli, L. (2004). Ecological notes on two colubrid snakes (Coluber viridiflavus and Elaphe longissima) in a suburban habitat (Rome, central Italy). The Herpetological Bulletin 87: 8-12.

Rugiero, L. \& Luiselli, L. (1995). Food habits of the snake Coluber viridiflavus in relation to prey availability. Amphibia-Reptilia 16: 407-411.

Umeton D, Read., J.C.A. \& Rowe, C. (2017). Unravelling the illusion of flicker fusion. Biology Letters. 13: 20160831. DOI: $10.1098 / \mathrm{rsbl} .2016 .0831$

Zhou W.Q., Huang G.L. \& Cadenasso, M.L. (2011). Does spatial configuration matter? Understanding the effects of land cover pattern on land surface temperature in urban landscapes. Landscape Urban Plan 102: 54-63. DOI: 10.1016/j.landurbplan.2011.03.009

Zuffi, M., Bresciani, E., Fornasiero, S. \& Dendi, F. (2007). Pheromone trailing in male European whip snakes, Hierophis viridiflavus. Amphibia-Reptilia 28: 555-559.

Accepted: 9 July 2021 